\title{
NUEVA RELACIÓN DE LA EMBAJADA \\ DE DON GARCÍA DE SILVA Y \\ FIGUEROA A PERSIA. 1619
}

\author{
POR
}

\author{
Manuel de Castro y Castro
}

Miembro C. de la Real Academia de la Historia

\section{RESUMEN}

Un franciscano, Fr. Melchor de los Ángeles, probablemente portugués, misionero en Persia, el año 1619, da un informe poco favorable a la célebre embajada de D. García de Silva Figuroa.

\begin{abstract}
Fr. Melchor de los Ángeles, Franciscan, perhaps portuguese, missionary in Persia, gives in 1619 a not much favourable statement about the famous embassy of D. García de Silva Figueroa.
\end{abstract}

Todos los intentos del gobierno de Felipe III de concertar una liga contra el turco fracasaron. El sah de Persia Abbas I (1586-1628) se alejo de España y se aproximó a Inglaterra y a Holanda, con grave riesgo para las posesiones de Portugal en Oriente. Este peligro impulsó a Cristóbal de Moure, virrey de Portugal $^{1}$ a solicitar el envío a Persia de una persona que desempeñase el papel de embajador permanente.

Se confió misión tan delicada a un diplomático de talento, don García de Silva y Figueroa. Como siempre, la embajada salió de Lisboa en una pequeña flota el 8 de abril de 1614, cargada de presentes para el sah, que debía averi-

I A H. OLIVIRA MARQUÉs, Historia de Portugal. I. Lisboa 1972, 429, 453-56. 
guar la situación y las defensas de la frontera de Ommuz, las relaciones entre el turco y el soberano persa y convencer a éste de la conveniencia de su alianza con España, manifestándole la ayuda que hasta entonces se le había prestado en las luchas contra el turco.

La flota fue costeando África y llegó a Goa (Indostán) en febrero de 1615, donde el gobemador portugués, aunque era vasallo de Felipe III, puso todas la dificultades posibles a la continuación de esta misión. El embajador, leal y enérgico, fletó con sus medios una pequeña nave y con ella prosiguió el viaje con su comitiva.

En la costa de Bardaz lo esperaba un emisario del soberano persa y con él se internó en Irán llevado en un palanquín hasta Ispahán, entonces capital de Persia, al tiempo que también llegaba a la ciudad el P. Femando Moraga, franciscano español misionero en Filipinas, a quien el embajador presentó al rey, y con este motivo, el 15 de junio de 1618 , se celebraron grandes fiestas que el $P$. Moraga $^{2}$ describe en su Grandioso presente y real embaxada...

El embajador español se dio cuenta del mal estado de las relaciones con los persas, porque se habían apoderado de Bahrien, Comarán y Queiscome, posesiones portuguesas que no querian devolver, pues en abril procuraron hacer la paz con los turcos, todo lo cual se describe en su obra ${ }^{3}$. El embajador español, cansado de evasivas, emprendió por Ormuz el regreso a la patria, que no alcanzó, pues en abril de 1624 le sorprendió la muerte en la costa de Loanda.

Quién llegó a España fue el P. Moraga, pues refiere León Pinelo4:

A 30 de enero de 1616 llegó a esta villa el M.F. Hernando Moraga, de la orden de s. Francisco, descalzo de la provincia de S. Gregorio de Filipinas, y trajo la Relación de la embajada que hizo a Persia D. García de Silva y Figueroa, con un rico y ostentoso presente que por la corona de Portugal hizo el rey al persa, que entró en su corte de Ispazán a 15 de junio de 1618 . Llevado de 400 personas y de 300 camellos. A todo lo cual se halló presente el P. Moraga.

Esta Relación del P. Moraga fue impresa en español, sin lugar ni año y, traducida al italiano, el año 1619, fue impresa en Miláns.

\footnotetext{
2 Lorenzo PÉREZ, OFM, De Filipinas a España. Naufragio de una armada en el siglo XVII. AIA (= Archivo Ibero Americano) 17(1922)288-320.

3 García de Silva y FIGUEROA, Comentarios de la embajada que de parte del rey de España Felipe II hizo al rey xa Abas de Persia. "La Sociedad de Bibliofilos Españoles". I. Madrid 1903, 271-84. II. Madrid 1903, 359-61. Madrid. Biblioteca Nac. R/15.170.

4 Antonio de LEÓN PINElo, Anales de Madrid (desde el año 447 al de 1658). Madrid 1971, 221.

\$ José SIMón DíAz, Bibliografia de la literatura hispánica. XV. Madrid 1992, 319. 
En la sección de manuscritos de la Biblioteca Nacional ${ }^{6}$ se conserva otra relación de la jornada de D. García de Silva firmada en Madrid el $\mathbf{3 0}$ de abril de 1619 por Fr. Melchor de los Ángeles que, al parecer, llegó a Madrid tres años más tarde que el $P$. Moraga.

No he conseguido identificar la personalidad de este misionero, pues no figura en el Catálogo de pasajeros a Indias a través de la Casa de la Contratación de Sevilla, ni en el catálogo de misioneros españoles que en el siglo XVI pasaron a Indias, publicado por el P. José Castro Seoane, OdeM, en "Missionalia hispanica".

Me inclino a creer que se trata de un misionero, probablemente franciscano portugués, a juzgar por algunas palabras que utiliza, como "annos", años; "min", por mi; "chama", que se llama. Se encontraba en Persia antes de que llegaran allí D. García y el P. Moraga, trataba personalmente al sah y da muestras de conocer las maneras de ser de los persas.

Simpatiza poco con el señor embajador, del que señala las equivocaciones, y ningunos éxitos en su empresa, por no ser de edad apropiada para ello, y por no tener en cuenta algunas orientaciones y advertencias que le hizo.

\section{0, diciembre, 1619. Madrid.}

Relación de la jornada de Don García de Sylva <y Figueroa>, embaxador, dada por Fr. Melchor de los Ángeles.

Madrid, Biblioteca Nac. Ms. 2348, 519-20v.

Después de estar dos annos en Goa por el virrey de la India no dar entero cumplimiento a sus despachos, se partí a Ormuz aonde liegó a 22 de Abril de 1617 y allí se detuvo cinco meses e medio, por causa de los calores, conforme me escribió.

A los 12 de Octubre del mismo año entró en la Persia, a donde desembarcando halló ya por orden del Rey de Persia aparejado todo el recaudo de caballos e camellos y gasto para las jomadas y quién lo acompañase, aposentándole y regalándole con todo cuidado. Y después de aver caminado 16 jornadas, se detuvo en Jira, por venir entrando el inviemo y el ser viejo. Alli estuvo otros cinco meses no pensando que perdía tanto como después vio, porque si entonces anduviera más veinte jornadas, llegara adónde estaba el Rey, y estando con él todo el invierno le sobrara tiempo para tratar despacio con el Rey y traher la respuesta de su embaxada, to que después no pudo hacer, porque quando se vio con el Rey, fue en Junio, encontrándole a tiempo que iba a recibir el Turco que entraba por sus tierras, y por esta causa no hubo lugar de hablar más que una vez con él, quando dio la carta y presentes de Su Magestad, y otra que le habló en la plaça, cstando solo once días en conpañia del Rey.

6 Manuel de CASTRO, OFM, Manuscrios franciscanos de la Biblioteca Nacional de Madrid. Valencia $1973,143, \mathrm{n}^{\circ} .128$. 
La edad que el Embaxador tiene y el cansancio y trabajo del camino le quitaron otra buena ocasión que se le ofreció, porque el Rey le envió a suplicar que pasase con él cinco o seis jornadas hasta Saltania adónde tenía st exército, prometiéndole que allí le despacharía. Escusose el Embaxador por causa de su edad y de tener enfermos sus criados, lo que el Rey sintió mucho. Siendo el Embaxador avisado desto, se ofreció acompañarle y entonces no quiso el Rey, y assí se partio a la guerra y el Embajador a Aspan. Y como el Rey después de acabar la guerra no se vino a Aspan, no ha habido lugar de verle más el Embaxador, pero en Junio passado de 1619 se esperaba que el Rey vendría a Aspan, adónde el Embaxador le hallaría y despacharía, porque así se lo embió el Rey a decir por min.

En Ormuz se le moría al Embaxador Deual (?) intérprete que su Magestad le dio en esta Corte, y luego recibió otro que se chama Joseph Saluador que estuvo por dos veces en esta Corte, al qual le mataron saliendo de jiras, y hallando otro muy suficiente, le pidió tanto que obligó al Embaxador a que le recibiese un armenio que, aunque sabía bien el Persiano sabía poco del Español, lo que el Rey conoció quando le hablaba y le dixo que pues no sabía aquel officio, porque le acusaba si no lo entendía.

Pareciole al Embaxador que no era decente llebar pimienta por presente al Rey de Persia, por ser cosa de mercaduría, y por esta causa dexó gran cantidad en Aspan que Su Magestad enviaba; todavía el Rey de Persia lo sintió, porque quisiera que el presente tuviera mucha obstentación, por hallarse en aquella ocasión el Embaxador del Turco y otros. Esta pimienta aún quedaba en poder del Embaxador quando yo me partí de Persia.

El Rey de Persia no es liberal. Con todo dio al Embaxador Don García de Sylva todo lo necesario en abundancia hasta llegar a su presencia, y aun no le falto con él los cinco meses que estuvo en jiras con tanto gasto, y después de llegar a su presencia le dio por dos veces en menos tiempo de un año, quinientos tumanes en dinero, que son ocho mil reales de a ocho, que allá valen doce mil conforme lo que vale la moneda. Demás desto le dio algunas cosas de valor, y entiendo que quando agora le despachare le dará doblado.

No puedo dexar de decir una cosa que el Embaxador hiço en Persia, lo que a mi parecer no convenía, como a él mismo se lo dixe por algunas veces, y es que entrando en Persia por qualquier culpa que sus criados los cometían en su casa, enviaba a llamar la justicia de los moros y se los entregaba para que los llevasen presos a sus cárceles, lo que ellos sufrian tan mal que entregando ... a su Secretario lo sintió tanto, que dixo delante de mi y de todos en voz alta que si le tratasen de aqueIla manera, se haría moro; y otros criados dijeron lo mismo en semejantes ocasiones, y alguno muy a peligro de hacerse moro si no le acudiéramos con breveda. De aquí nació que hallando la Justicia de Aspan un criado del Embaxador de noche en casa de una muger, le hiço pasar por la plaça con las manos atadas con un pregón afrentoso, y quejándose al Emjador deste agravio él respondió al Govemador que pues él lo llamaba a su casa para castigar sus criados, no le hacían agravio en castigar aquel que hallaban culpado.

Quanto a sus pagamentos entiendo que el virrey le pagó primero saliere de Goa la mayor parte de lo que se le debia, por quanto le habían detenido y no le pagaban.

En llegando a Ormuz le pagó Don Luis de Gaona quince mil pardaos de larines que son cerca de veinte mil ducados, y después de estar en Persia dentro de un año le habían enviado más de diez mil ducados, así que entiendo que solamente de veinte mil ducados que llebó para gastos extraordinarios de la Embaxada, se le deben todos o la mayor parte dellos, de lo que se quexa de ordinario.

Y por quanto todo esto pasa en la verdad, sin aver otra cosa en contrario, lo firmé en Madrid, a los 30 de Diziembre de 1619. Fr. Melchor de los Ángeles.

La época de Felipe H y los Austrias

Hispania Sacra 50 (1998) 